\title{
Bidirectional Turbulent Fluxes of Fog at a Subtropical Montane Cloud Forest Covering a Wide Size Range of Droplets
}

\author{
Maiken Baumberger ${ }^{1}$ (D) Bettina Breuer ${ }^{1}$ (D) Yen-Jen Lai ${ }^{2}$ (D) \\ Dmitrii Gabyshev $^{3}$ (D) Otto Klemm ${ }^{1}$ (D)
}

Received: 21 December 2020 / Accepted: 27 July 2021 / Published online: 30 August 2021

(c) The Author(s) 2021

\begin{abstract}
Size-resolved turbulent fluxes of fog droplets are investigated above a subtropical montane cloud forest in Taiwan. By integrating an aerosol spectrometer into an eddy-covariance setup, we measure droplet number fluxes and liquid water fluxes in a size range of aerosol particles and droplets with diameters ranging from $0.25 \mu \mathrm{m}$ to $17.3 \mu \mathrm{m}$. We find two fluxdirection changes within this size range: a downward flux occurs for accumulation-mode aerosols of diameters between $0.25 \mu \mathrm{m}$ and $0.83 \mu \mathrm{m}$, an upward flux occurs for hydrated aerosols with diameters between $1.1 \mu \mathrm{m}$ and $2.4 \mu \mathrm{m}$, and a downward flux occurs again for activated fog droplets between diameters of $3 \mu \mathrm{m}$ and $17.3 \mu \mathrm{m}$. The droplet size distributions can be modelled by a trimodal log-normal distribution, and the modes correlate with the different flux directions. The formation of the three modes and the establishment of the respective flux directions can be explained by combining the Köhler theory on the basis of measured ion concentrations in fog with the turbulent transport of droplets. Finally, from the combined analysis of droplet fluxes and size distributions, we infer relevant processes of droplet development and dissolving during various phases of the life cycles of the fog events.
\end{abstract}

Keywords Eddy covariance $\cdot$ Fog-droplet distribution $\cdot$ Fog-droplet fluxes $\cdot$ Mountain fog

\section{Introduction}

Fog is of great importance, both locally and globally: it is an essential source of water for plants (Ju et al. 2012), animals (Parker and Lawrence 2001), and entire ecosystems (Dawson 1998) and has been utilized for human water supply (Klemm et al. 2012). Fog also affects

Maiken Baumberger

maiken.baumberger@uni-muenster.de

1 Institute of Landscape Ecology - Climatology Research Group, University of Münster, Heisenbergstraße 2, 48149 Münster, Germany

2 Experimental Forest, National Taiwan University, 55750 Nantou, Taiwan

3 Institute of Environmental and Agricultural Biology (X-BIO), University of Tyumen, Volodarsky Str. 6, Tyumen, Russia 625003 
man-made traffic systems on land (Ahmed et al. 2014), sea (Rømer et al. 1995), and in the air (Fultz and Ashley 2016). Moreover, fog affects the net radiation on Earth by reflecting shortwave radiation (Klemm et al. 2006). Additionally, an ecosystem's energy balance is affected by fog: during fog, sensible and latent heat fluxes decrease, whereas during fog dissipation they increase (Gultepe et al. 2016). In most parts of the world, however, the occurrence of fog has decreased over the past years to decades, and the causes for this trend are not fully understood (Hanesiak and Wang 2005; Vautard et al. 2009; Klemm and Lin 2016). Certainly, physical and chemical conditions (temperature, humidity, and the number, size, and chemical composition of condensation nuclei) of potentially foggy airmasses are important drivers of the occurrence of fog (Gultepe et al. 2007). Therefore, understanding the microphysics of fog in detail is of great importance in atmospheric-boundary-layer research.

From a meteorological point-of-view, fog is a cloud in contact with the ground and is described as a suspension of small droplets or ice crystals that reduces the horizontal visibility to below $1000 \mathrm{~m}$ (World Meteorological Organization 1992; Gultepe et al. 2016). Fog occurs in the lower part of the boundary layer when air is supersaturated with respect to its water vapour concentration and when cloud condensation nuclei (CCN) are present (Hudson 1980). Hydrated aerosols develop and grow as a result of condensation and coalescence. Due to supersaturation, hydrated aerosols can be activated and become fog droplets (Hammer et al. 2014).

Different types of fog are defined by their formation processes and geographical location of occurrence (Bruijnzeel et al. 2006; Eugster 2008). In the subtropic montane cloud forests of Taiwan, mountain fogs occur frequently, especially in the region of Xitou (Wey et al. 2011). Mountain fog may form when oceanic airmasses stream into the mountain valleys, ascend and therefore cool, which may lead to condensation (Bruijnzeel et al. 2006). The frequent formation of fog in Xitou makes the region suitable for fog research (Wey et al. 2011; Simon et al. 2015; Maneke-Fiegenbaum et al. 2018; Chen et al. 2021). Note that fog at Xitou is enriched with a considerable level of pollutants because the airmasses travel over the densely populated and industrialized regions of western Taiwan before they arrive in the mountain range (Simon et al. 2015).

One field of interest in fog research is the microphysics of fog droplets and their size distribution. Aerosol particles generally exist in different modes, which is a result of multiple origins and formation processes (Seinfeld and Pandis 2016). Likewise, the droplet size distribution of fog can be described by a bimodal or trimodal log-normal distribution (also depending on the measurement range): Eldridge (1966) observed bimodal and trimodal fogdroplet size distributions determined by the state of formation and also by the type of fog. Elias et al. (2015) and Hammer et al. (2014) reported a bimodal fog-droplet size distribution and identified the modes as hydrated aerosols (which are smaller, non-activated droplets) and larger activated fog droplets. They identified transition diameters between $1 \mu \mathrm{m}$ and $5 \mu \mathrm{m}$.

Quantifying the deposition of fog onto the underlying surface can be done directly with an eddy-covariance set-up that integrates a droplet-size-resolving device, yielding droplet number fluxes (DNFs; which also include non-hydrated aerosol particle number fluxes for smaller size classes) and liquid water fluxes (LWFs). In general, fog develops in the atmosphere and deposits into the ecosystem, but Vong and Kowalski (1995), Klemm and Wrzesinsky (2007), Beiderwieden et al. (2008), Westbeld et al. (2009), Degefie et al. (2015a), and El-Madany et al. (2016) detected upward fluxes of the smaller fog droplets (in most studies droplet diameters $<8 \mu \mathrm{m}$ ) of their measurement range. Upward fluxes of smaller fog droplets thus coexist with downward fluxes of fog droplets of larger sizes (Beiderwieden et al. 2008; El-Madany et al. 2016). El-Madany et al. (2016) explained the development of bidirectional fog DNFs at a site in Taiwan, similar to Xitou, as follows: hydrated aerosol particles are transported 
upwards through turbulent motion and grow by condensation because they reach a cooler, more humid airmass. They may grow larger than their critical diameter due to supersaturation in higher airmasses and, thus, be activated. These larger, activated droplets grow rapidly by condensation and may be transported back down by a turbulence element. Due to activation, they are able to exist even at a lower relative humidity than the critical supersaturation and are stable during downward transport as long as the relative humidity is larger than $100 \%$. The critical droplet diameter for droplet activation can be calculated using the Köhler theory, which describes the equilibrium droplet size as a function of its chemical composition and the relative humidity in the surrounding air (Köhler 1921).

The present study provides new insight into fog-droplet fluxes by combining data of DNFs with modelled fog-droplet size distributions. Our aerosol sensor has a measurement range that includes even smaller droplet sizes than previously considered (e.g., Beiderwieden et al. 2008; El-Madany et al. 2016). The combination of an aerosol spectrometer and an anemometer enables droplet flux measurements by the eddy-covariance technique (Sects. 2.2, 2.3, and 2.4). The observed size-dependent fog-droplet fluxes show two changes of the flux direction within the resolved size range (Sects. 3.2 and 3.3). One of the transition points matches well with the observations cited above, whereby smaller droplets are moving upward while larger droplets tend to deposit. Yet, we also discovered a second change of flux direction for smaller particles in a so-far undetected size range. The two flux directions match well with the three modes of the modelled droplet size distribution (Sect. 3.7). We explain this by the process of condensational droplet growth and activation during turbulent transport (Sects. 4.2 and 4.3). Finally, we discuss the processes of development and dissipation of fog based on the combined analysis of fog-droplet fluxes and size distributions (Sect. 4.4).

\section{Methods}

\subsection{Site Description}

The measurement tower $\left(23^{\circ} 39^{\prime} 52^{\prime \prime} \mathrm{N}, 120^{\circ} 47^{\prime} 44^{\prime \prime} \mathrm{E}\right)$ is located in the Experimental Forest of the National Taiwan University in Xitou, in the centre of Taiwan (Fig. 1a, b). The surrounding area is a coniferous forest which covers 2400 ha. Around 620 ha consist of natural hardwood forest and the rest is plantations of Cryptomeria japonica, Taiwania cryptomerioides, Chamaecyparis formosensis, Cunninghamia lanceolata and Cunninghamia konishii (Liang et al. 2009).

The study area is located in a valley with an orientation from south-south-west (upper part) to north-north-east (lower part). It ranges in elevation from $500 \mathrm{~m}$ to $2025 \mathrm{~m}$ above sea level (a.s.1.) and has a slope of $9.4^{\circ}$ (Maneke-Fiegenbaum et al. 2018). The 40-m high meteorological tower is located at $1267 \mathrm{~m}$ a.s.l. The canopy height around the tower is about $28 \mathrm{~m}$. Considering the geometry of the forest's canopy, we estimate a displacement height of $22 \mathrm{~m}$ and a roughness length of $0.14 \mathrm{~m}$.

The measurements took place between 27 July 2019 and 19 August 2019. The annual mean temperature at the site is $16.6^{\circ} \mathrm{C}$. The mean maximum $20.8^{\circ} \mathrm{C}$ in July and mean minimum $12^{\circ} \mathrm{C}$ in January. The mean annual precipitation is $2635 \mathrm{~mm}$. There is a wet season between May and September and a dry season from October to April (Wang et al. 2011). The site is subjected to a daily mountain-valley flow: during daytime, the valley flow is from the north, and during the night-time the mountain flow is from the south. Fog typically occurs in the 


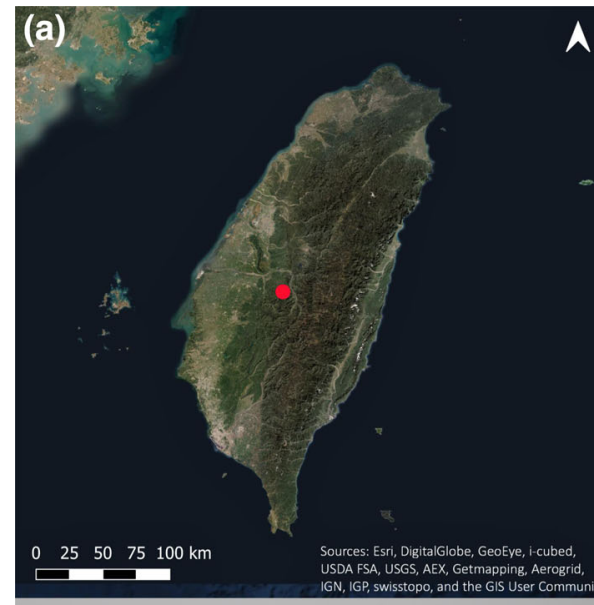

(c)

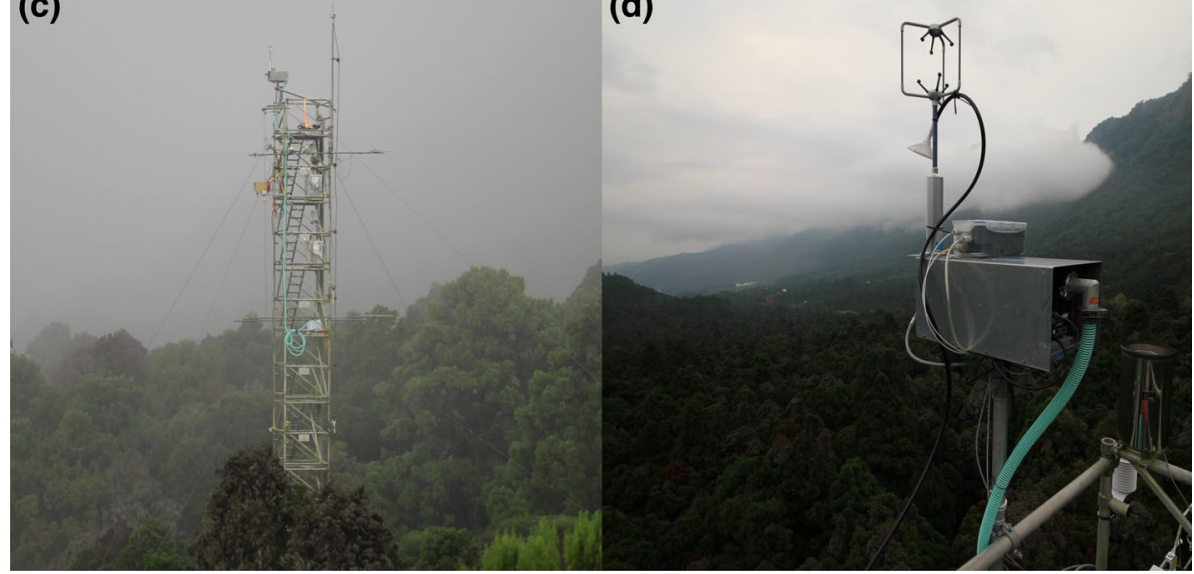

Fig. 1 a Location of the measurement tower shown on a satellite image of Taiwan. b Location of the measurement tower indicated on a satellite image showing the region of Xitou. $\mathbf{c}$ Photograph of the measurement tower above the canopy. d Flux-measurement set-up on the top of the tower

late afternoon, when the upslope valley flow is from the north and orographic fog forms (Wey et al. 2011).

\subsection{Experimental Set-up}

The set-up for measuring the turbulent fog droplet fluxes was installed on the top of the 40-m high tower, $12 \mathrm{~m}$ above the canopy (Fig. 1c, d).

The eddy-covariance set-up included a three-dimensional sonic anemometer (R3-50, Gill Instruments, Ltd. Lymington, Great Britain) which measures the three wind components ( $u$, $v, w)$, sonic temperature, sensible heat flux, friction velocity, and momentum flux. It was installed on the top of the tower on a metal frame, so it reached a height of $42.8 \mathrm{~m}$ above ground. The data were sampled on a data logger (CR3000, Campbell Sci. Inc., Logan, Utah, USA). The set-up also included a spectrometer which counts size-resolved numbers of aerosol particles (including droplets) (WELAS aerosol sensor 2300, PALAS GmbH, Kahlsruhe, 
Table 1 Measurement instruments with specifications

\begin{tabular}{|c|c|c|c|c|}
\hline Instrument & Producer & Temporal resolution & Observed parameters & Uncertainty \\
\hline Sonic Anemometer & Gill & $10 \mathrm{~Hz}$ & Wind speed $(U)$ & $U:<1 \%$ RMS \\
\hline \multirow[t]{2}{*}{ R3-50 } & Instruments & & Wind direction $(\phi)$ & (at $12 \mathrm{~m} \mathrm{~s}^{-1}$ ) \\
\hline & & & & $\phi:< \pm 1^{\circ} \mathrm{RMS}$ \\
\hline WELAS Aerosol & PALAS & $10 \mathrm{~Hz}$ & Aerosol number & $20 \% *$ \\
\hline Sensor 2300 & $\mathrm{GmbH}$ & & size distribution & \\
\hline \multirow[t]{2}{*}{$\mathrm{HC} 2 \mathrm{~S} 3$} & Campbell & $10 \mathrm{~min}$ & Air temperature $(T)$ & $T: \pm 0.1 \mathrm{~K}$ \\
\hline & Sci. Inc. & & Relative humidity $(r H)$ & $r H: \pm 0.8 \%$ \\
\hline Present Weather & Vaisala & $1 \mathrm{~min}$ and $10 \mathrm{~min}$ & Horizontal visibility & $\pm 10 \%$ \\
\hline Detector PWD11 & & & & \\
\hline
\end{tabular}

*Elias et al. (2009)

Germany, referred to as the WELAS sensor in the following). Its intake flowrate of air is $5 \mathrm{~L} \mathrm{~min}^{-1}$; the detection of particles is based on a scattered-light analysis of single particles (Mölter and Keßler 2004). The calibration was performed with standard monodisperse test dust (Mono-Dust 1500, PALAS GmbH, Kahlsruhe, Germany). The intake opening of the WELAS sensor is orientated to the north, the direction from which the foggy airmasses typically come. The sensor was also installed on the top of the metal frame at $42.2 \mathrm{~m}$ above ground level (a.g.l.), which was $0.6 \mathrm{~m}$ below the anemometer to prevent disturbance to the wind measurement. In the configuration we used for the measurements at Xitou, the spectrometer had 255 size channels in a particle diameter size range from $0.15 \mu \mathrm{m}$ to $17.6 \mu \mathrm{m}$, subdivided logarithmically. This size rage includes non-hydrated aerosol particles, hydrated aerosol particles, and activated fog droplets. The latter two types are fog droplets due to their potential to reduce visibility. Due to the higher portion of the fog droplets and the focus of this study, aerosol particles of the whole size spectrum are referred to as fog droplets in the following. Wind and droplet data were sampled with a frequency of $10 \mathrm{~Hz}$ (cf. Table 1).

While the R3-50 sonic anemometer has been reported to show a good performance under foggy conditions (El-Madany et al. 2013), the WELAS sensor is not typically used for in situ fog measurements. The droplet spectrometer (FM100 Fog Monitor, Droplet Measurement Technology, Boulder, Colorado, U.S.A.) is more commonly used for fog-droplet flux measurements (e.g., Beiderwieden et al. 2008; Westbeld et al. 2009; Degefie et al. 2015b; El-Madany et al. 2016); here, the WELAS sensor was chosen due to its measurement range, which covers aerosol particle diameters down to $0.15 \mu \mathrm{m}$ and, thus, the full size range of interest here. The WELAS sensor also provides a $10-\mathrm{Hz}$ measurement frequency, which is required for eddy-covariance flux measurements. Haeffelin et al. (2010) and Elias et al. (2015) showed the usefulness of the WELAS sensor for fog studies in the field. Zhang et al. (2014) argued that droplets larger than $8 \mu \mathrm{m}$ are not accurately measured by the WELAS sensor. The instrument was calibrated with monodisperse test dust (refractive index 1.59, Flores et al. 2009) which has the same characteristics as non-hydrated aerosol particles. However, we also measured water droplets (refractive index of pure water 1.33, Seinfeld and Pandis 2016). This led to an increasing divergence of the actual droplet diameter and the measured 
droplet diameter with increasing size: the largest droplets of $17 \mu \mathrm{m}$ were measured up to $20 \%$ larger than their real diameter.

Additional meteorological parameters we measured were air temperature, relative humidity, and visibility. All devices were installed on top of the tower. A temperature and relative humidity probe (HC2S3, Campbell Sci. Inc., Logan, Utah, U.S.A.) was installed on the north-eastern side of the tower. The visibility was measured by a Present Weather Detector (PWD11, Vaisala, Helsinki, Finland), and the data were averaged over intervals of $1 \mathrm{~min}$ and 10 min, respectively (cf. Table 1 ).

\subsection{Data Processing}

In total, data were collected over a period of 23 days from which we chose for further analyses four fog events with good data quality during three different days (14, 15, and 19 August 2019).

The smallest 44 channels and the largest channel of the WELAS sensor did not detect any particles and were thus removed from the dataset. The remaining 210 channels were combined into 21 classes with 10 channels each (cf. Table 2) in order to improve counting statistics. The combined channels exhibited sufficiently high numbers of detected droplets for the eddy-covariance-flux calculation (cf. Deventer et al. 2013). The output data of the spectrometer comprise detected counts of aerosol particles for each size bin per sampling interval. To obtain a number concentration of particles, the detected counts per time were divided by an effective volume flow rate of the particles, specified by the velocity of the particles and the geometry of the measurement chamber (Mölter and Keßler 2004).

\subsection{Flux Calculation and Quality Control}

Turbulent fluxes of fog droplets were calculated by the eddy-covariance method (Foken et al. 2012). The fluxes result from the covariance of the vertical wind component and the number of fog droplets of each size class. The software used for the flux calculation was "EddyUH", version 1.7 (Mammarella et al. 2016), the settings are specified in the following. The employed dataset includes the processed data at a $10-\mathrm{Hz}$ resolution, as described in Sect. 2.3, from 12 to 19 August 2019. Fluxes were calculated for averaging periods of $15 \mathrm{~min}$. Fifteen-minute intervals were chosen due to the combined analysis of fluxes and the distribution of fog droplets: for shorter intervals, large turbulence elements of the turbulence spectrum are not resolved, whereas for longer intervals, the size distribution is no longer suited for modelling due to stationarity issues. Rapid changes in fog properties are better reflected in 15-min intervals than in 30-min intervals, which are typically used for the eddycovariance technique. For post-processing, despiking was done by the method of Vickers and Mahrt (1997). In order to eliminate a trend over the period and to guarantee a stationary interval, linear detrending was applied. For coordinate rotation of the wind data, the planar-fit method was used (Wilczak et al. 2001). Rotation was applied for the whole measurement period and was selected to compensate for the slope of the site and the inclination of the anemometer. A correction was applied to the data for air density fluctuations (Webb et al. 1980). For the flux calculation, spectral corrections (scalar model cospectrum and cospectral peak frequency versus stability parametrization) were performed by the methods of Horst (1997). High and low frequency losses were corrected by a theoretical transfer function according to Moncrieff et al. (1997) and Rannik and Vesala (1999). To correct the lag time between the anemometer and the WELAS sensor, a manual estimation was given, and the 
Table 2 Combined size classes of the WELAS device with the top threshold of droplet diameter in $\mu \mathrm{m}$ and channel width in $\mu \mathrm{m}$

\begin{tabular}{|c|c|c|}
\hline Class & $\begin{array}{l}\text { Top threshold } \\
\text { droplet diameter }(\mu \mathrm{m})\end{array}$ & $\begin{array}{l}\text { Width } \\
\text { of channel }(\mu \mathrm{m})\end{array}$ \\
\hline 1 & 0.25 & 0.03 \\
\hline 2 & 0.29 & 0.04 \\
\hline 3 & 0.33 & 0.04 \\
\hline 4 & 0.37 & 0.04 \\
\hline 5 & 0.44 & 0.07 \\
\hline 6 & 0.54 & 0.10 \\
\hline 7 & 0.67 & 0.13 \\
\hline 8 & 0.83 & 0.16 \\
\hline 9 & 1.06 & 0.23 \\
\hline 10 & 1.46 & 0.40 \\
\hline 11 & 1.93 & 0.47 \\
\hline 12 & 2.43 & 0.50 \\
\hline 13 & 2.98 & 0.55 \\
\hline 14 & 3.73 & 0.75 \\
\hline 15 & 4.78 & 1.05 \\
\hline 16 & 5.99 & 1.21 \\
\hline 17 & 7.35 & 1.36 \\
\hline 18 & 9.11 & 1.76 \\
\hline 19 & 11.64 & 2.53 \\
\hline 20 & 14.46 & 2,82 \\
\hline 21 & 17.33 & 2,87 \\
\hline
\end{tabular}

maximum of the cross-covariance function was searched within the lag time window. The quality flags were also set by the EddyUH software. The flux stationarity test was selected since it is, in contrast to the integral turbulence characteristics, not corrupted by the slope of our measurement site (Foken and Wichura 1996; Foken et al. 2005). The quality flags range from 1 (best) to 9 (worst) as defined by Foken et al. (2005). Data with quality flags of 7 and higher were set to NA. Thus, only data of good and very high quality were included in the analysis.

\section{Results}

We present the two fog events from 19 August 2019 in more detail. In Sect. 3.1, we present the meteorological conditions of this specific day. In the subsequent section, we show averaged flux data of all fog events. The results exhibit two DNF direction changes within the measured droplet size range and a persistent downward overall LWF, which is dominated by the larger droplet classes. As an example of time-resolved DNFs, we present data for 19 August 2019 in Sect. 3.3. The quality flags and the uncertainties of the size-resolved DNFs are shown in Sects. 3.4 and 3.5. Moreover, the qualitative change of the size-resolved fogdroplet distribution during one fog event is described in Sect. 3.6. Then, the fog-droplet size distribution was fitted by a model which was then linked to the DNFs (Sect. 3.7). Finally, in 

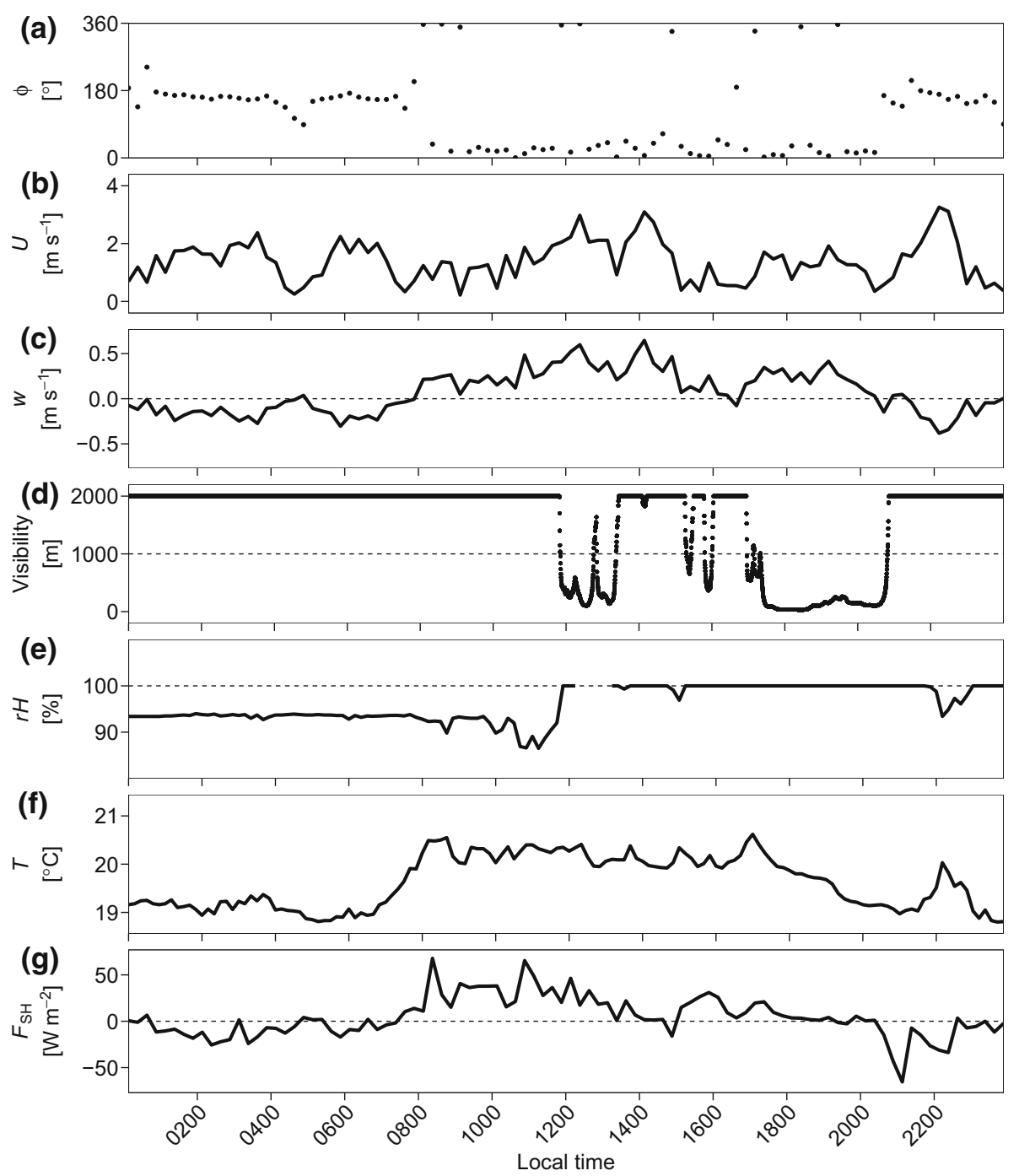

Fig. 2 Meteorological parameters for 19 August 2019: a 15-min mean of the wind direction $(\phi)$, b 15-min mean of the total wind speed $(U), \mathbf{c} 15$-min mean of the vertical velocity component ( $w$; pre-planar-fit), d 10 -min mean of the visibility (dashed line marks the threshold for fog), e 10-min mean of the relative humidity $(r H), \mathbf{f} 10$-min mean of the temperature $(T), \mathbf{g} 15$-min mean of the sensible heat flux $\left(F_{\mathrm{SH}}\right)$

Sect. 3.8, the correlation of the modelled droplet size distribution and the DNFs is illustrated for the temporal evolution of the two fog events of 19 August 2019.

\subsection{Meteorological Conditions}

A distinct mountain-valley flow is usually present at the measurement site, which results from warming and cooling of airmasses over the mountain and valley (Whiteman and Zardi 2013). During the night-time of 19 August 2019, the flow came from the south, and at 

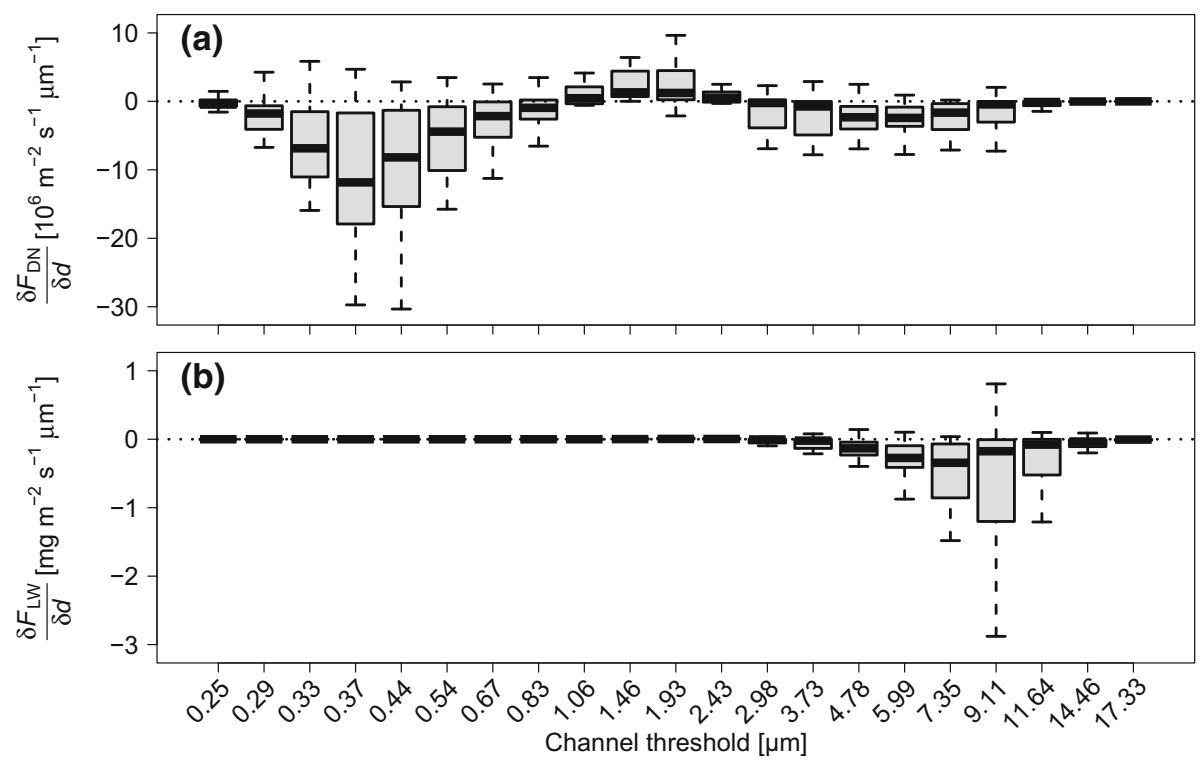

Fig. 3 a Averaged normalized size-resolved DNFs, b averaged normalized LWFs for foggy conditions (visibility $<1000 \mathrm{~m}$ ) of 15, 16, and 19 August 2019. Boxplots show the medians (black lines), the upper and lower quartiles (grey boxes), and the minima and maxima (whiskers) ignoring outliers

0730 LT (local time $=$ UTC +8 h) it changed its direction until 2030 LT, such that the flow came from the north during daytime (cf. Fig. 2a). Together with the changing wind direction in the morning, turbulence started developing (data not shown here). The mean wind speed $(U)$ varied highly between about $0.5 \mathrm{~m} \mathrm{~s}^{-1}$ and $3.5 \mathrm{~m} \mathrm{~s}^{-1}$ during the day (cf. Fig. 2b). As shown in Fig. 2c, f and g, the vertical velocity component ( $w$; pre-planar-fit), the temperature $(T)$ and the turbulent sensible heat fluxes $\left(F_{\mathrm{SH}}\right)$ also followed the wind direction change. The vertical velocity component was slightly negative when the flow came from the south and slightly positive when the flow was from the north. The temperature started rising at about 0700 LT and decreased again around 1700 LT. During night-time, the sensible heat flux was mostly negative and changed to a positive flux at 0730 LT, shortly after sunrise. Thus, the sensible heat flux was mostly positive even during foggy conditions (visibility $<1000 \mathrm{~m}$ ). Moreover, the boundary layer was not stable (not shown here) which indicates, in combination with a positive sensible heat flux, that the fog was of an orographic nature. On 19 August 2019, two fog events were observed at the height of the measurement tower: the first one lasted from 1150 LT to 1322 LT and the second one from 1658 LT to 2049 LT (cf. Fig. 2d). With decreasing visibility towards the beginning of first fog event, the relative humidity increased to $100 \%$. Until 2200 LT, the relative humidity remained at around $100 \%$ (precise value unknown in the data gap, but the existence of fog there suggests a relative humidity of around $100 \%$ ).

\subsection{Averaged Size-Resolved Fog-Droplet Fluxes}

Figure 3 shows the averaged normalized DNFs (a) and the averaged normalized LWFs (b) for each size class under foggy conditions. The calculated DNFs and LWFs of four fog events 
in 2019 were selected and averaged over all 15-min intervals for which the mean visibility was below $1000 \mathrm{~m}$ :

- 15 August, 1700 LT to 1845 LT (105 min),

- 16 August, 1700 LT to 1830 LT (90 min),

- 19 August, 1145 LT to 1330 LT (105 min),

- 19 August, 1645 LT to 2100 LT (255 min).

In total, the mean DNF was $-48.2 \times 10^{6} \mathrm{~m}^{-2} \mathrm{~s}^{-1} \mu \mathrm{m}^{-1}$ and the mean LWF was $-2.4 \mathrm{mg} \mathrm{m}^{-2} \mathrm{~s}^{-1} \mu \mathrm{m}^{-1}$. The direction of the DNFs depended on the droplet size. Altogether, we find two changes in flux direction within the analyzed droplet size spectrum: small, non-hydrated aerosol particles between channel thresholds of $0.25 \mu \mathrm{m}$ and $0.83 \mu \mathrm{m}$ (in the following called the small size classes) exhibit a downward flux with the largest median flux of $-11.84 \times 10^{6} \mathrm{~m}^{-2} \mathrm{~s}^{-1} \mu \mathrm{m}^{-1}$ for the size class $0.37 \mu \mathrm{m}$. Between top thresholds of $1.1 \mu \mathrm{m}$ and $2.4 \mu \mathrm{m}$ (in the following referred to as the middle size classes), we find, on average, upward fluxes. Here, the hydrated aerosol particles with a threshold of $1.5 \mu \mathrm{m}$ had the maximum positive flux with a median of $1.3 \times 10^{6} \mathrm{~m}^{-2} \mathrm{~s}^{-1} \mu \mathrm{m}^{-1}$. Larger size classes from $3 \mu \mathrm{m}$ to $17.3 \mu \mathrm{m}$ (in the following termed the large size classes) exhibit a negative flux, just like the small size classes. However, the normalized downward DNFs of the larger size classes are much lower and have a lower variance than the normalized negative DNFs of the smaller size classes. Droplets with an upper threshold of $6 \mu \mathrm{m}$ have a median DNF of $-2.4 \times 10^{6} \mathrm{~m}^{-2} \mathrm{~s}^{-1} \mu \mathrm{m}^{-1}$.

Liquid water fluxes differed substantially from DNFs within the studied size range due to the cubic dependency of the volume on the diameter: within the small size classes, we find very small negative LWFs (not even discernible in the graph) and in the middle size classes only slightly positive fluxes. However, the large size classes show negative fluxes up to a median of $-0.34 \mathrm{mg} \mathrm{m}^{-2} \mathrm{~s}^{-1} \mu^{-1}$. Clearly, the total LWF is dominated by the larger size classes.

\subsection{Evolution of Size-Resolved Droplet Number Fluxes During Fog}

The evolution of the size-resolved DNFs during the course of 19 August 2019 (cf. Fig. 4c) also showed the size-dependent flux directions. For the small aerosol particle classes a negative flux dominated, but within some 15-min intervals, especially towards the end of the fog events, a positive flux also occurred. The rise in magnitude of the DNFs of the middle and large size classes is associated with the formation of fog. Before the first fog event started, the fluxes were around zero or could not be calculated due to an insufficient number of detected droplets (15-min intervals before $1145 \mathrm{LT}$ ). When fog occurred at $1150 \mathrm{LT}$, we find positive DNFs in the middle size classes and negative DNFs in the larger size classes. At the end of the first fog event (around 1330 LT), the downward fluxes of the larger size classes vanished, and a positive flux is observed throughout the middle and smaller size classes. When for a short moment, visibility dropped below $1000 \mathrm{~m}$, downward fluxes of the larger size classes developed again (in 15-min intervals starting at 1500 LT and 1545 LT). Within the first part of the second fog event, a clear formation of two flux directions (downward, upward, downward for the respective size classes) occurred. When visibility increased slightly (around 1930 LT), the fluxes dropped to nearly zero, except for the fluxes of the smallest and largest size classes. This is simply due to the fact that at that time, almost no droplets were detected (cf. Fig. 4b). At the end of the second fog event (around 2100 LT), all fluxes were again around zero for the same reason. 
(a)

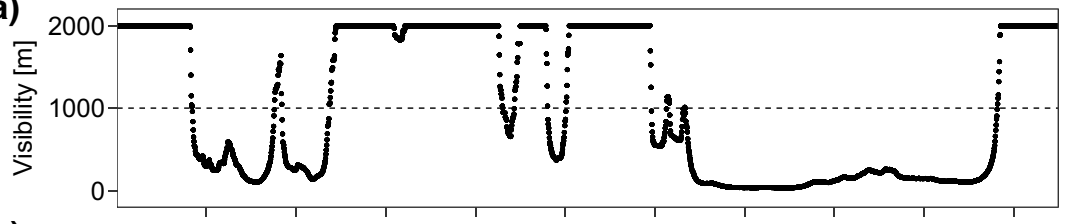

(b) $17.33-$ $14.46-$ $09.11-$ $07.35-$

金 05.99

03.73

02.98

$02.43-$

01.93

01.46

ब 01.06

$00.83-$

帘 00.67

00.44

00.37

00.33

00.29

00.25

(c)

17.33
14.46
11.64

09.11 -

07.35

金 04.78

증 04.78

02.98

02.43

01.93

01.46

ब 01.06

00.83

00.67

00.54

00.44

00.37

$00.33-$

00.29 -

00.25
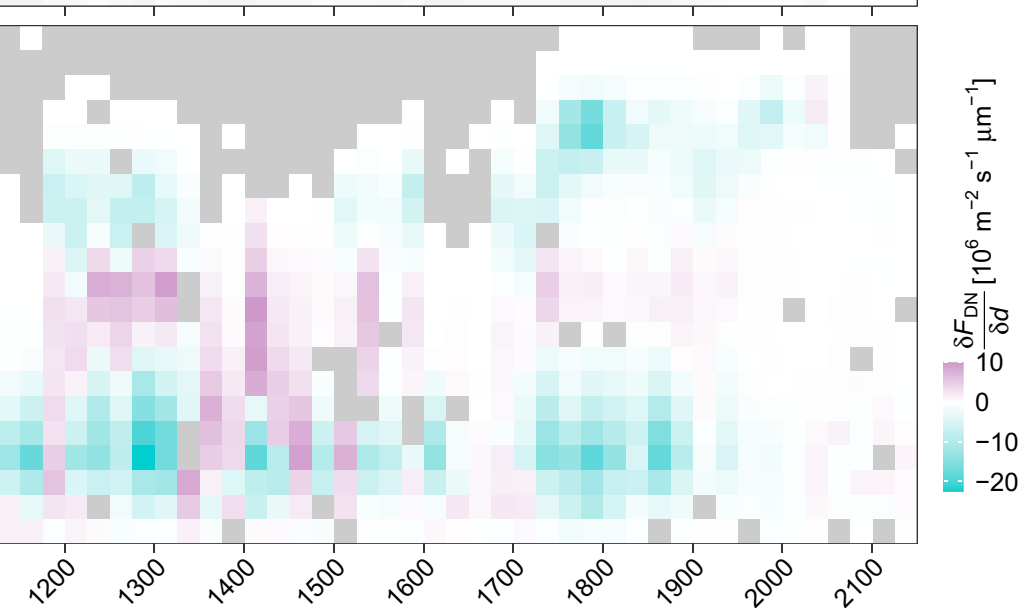

300

200

100

0

Local time

Fig. 4 Evolution on 19 August 2019 between 1100 LT and 2130 LT of a visibility (dashed line marks visibility of $1000 \mathrm{~m}$ ), b normalized size-resolved fog-droplet number concentration, and c normalized size-resolved fog-droplet number flux. Grey patches in $\mathbf{c}$ indicate data for which the calculation of fluxes is not possible due to an insufficient number of detected droplets or unmet quality standards

\subsection{Quality Flags}

As described in Sect. 2.4, quality flags ranging from 1 (best) to 9 (worst) were given by the flux stationarity test implemented in the EddyUH software. Figure 5 shows the fractions of the quality classes of the flux data during foggy conditions, and grouped into very high quality (1-3), good quality (4-6), and poor quality (7-9) according to Foken et al. (2005). Except for the two largest size classes, all size classes have a majority (around 80\%) of the best quality flags. 


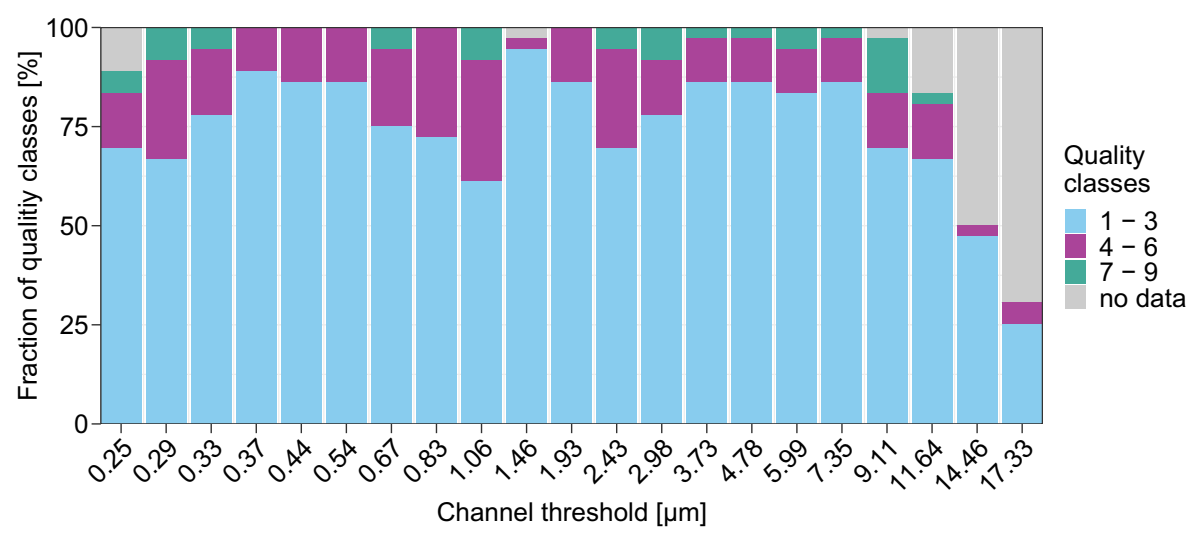

Fig. 5 Fractions of the quality classes for the fluxes of each size class under foggy conditions. The quality classes are summarized into three groups: classes 1-3 in blue show the part of the flux data that are of very high quality, classes 4-6 in purple show the part of the flux data of good quality, and classes 7-9 in green show the part of the flux data of poor quality. The fraction in grey indicates data for which the calculation of fluxes and, consequently, a calculation of a quality class was not possible

\subsection{Flux Uncertainty}

To evaluate the accuracy of the fog-droplet fluxes, uncertainties were determined in intervals of $15 \mathrm{~min}$ for the 21 droplet size classes. The uncertainties were calculated only for foggy conditions, i.e., when the visibility was below $1000 \mathrm{~m}$. The calculations included the four selected fog events (cf. Sect. 3.2). The calculated uncertainties are averaged for every size class and over the time of the selected fog events.

Discrete counting implies an uncertainty in number concentration measurements (Hinds 1999), which is described by

$$
\delta(N)=\frac{1}{\sqrt{N}} .
$$

Here, $\delta(N)$ is the relative uncertainty in number concentration and is calculated separately for each size class, with $N$ being the sum of detected fog droplets for every 15-min time period in the class.

The median of the uncertainty in number concentration ranges from $1.4 \%$ to $23 \%$. Channels 2 through 18 exhibit values of uncertainties well below 10\%. Only the smallest channel and the three biggest channels exhibit larger uncertainties of around 20\% (not shown here).

The relative number flux uncertainty $\left(\delta\left(\overline{w^{\prime} C_{N}^{\prime}}\right)\left(\overline{w^{\prime} C_{N}^{\prime}}\right)^{-1}\right.$ in \%) due to limited counting statistics was calculated according to Buzorius et al. (2003) and Deventer et al. (2013) as

$$
\frac{\delta\left(\overline{w^{\prime} C_{N}^{\prime}}\right)}{\overline{w^{\prime} C_{N}^{\prime}}}=\frac{\sigma_{w} \overline{C_{N}}}{\sqrt{N}\left(\overline{w^{\prime} C_{N}^{\prime}}\right)},
$$

with the standard deviation of the vertical velocity component $\left(\sigma_{w}\right)$, the mean of the droplet concentration $\left(\overline{C_{N}}\right.$ in droplets $\left.\mathrm{m}^{-3}\right)$, and the number flux $\left(\overline{w^{\prime} C_{N}^{\prime}}\right.$ in droplets $\left.\mathrm{m}^{-2} \mathrm{~s}^{-1}\right)$.

In Fig. 6, the relative uncertainties of the number fluxes as calculated using Eq. 2 are shown. The median of the relative number flux uncertainty ranges from of $3.4 \%$ to $44.1 \%$. Once again, the largest uncertainties occur in the smallest and largest size classes, while the uncertainties of all other classes are considerably lower. 


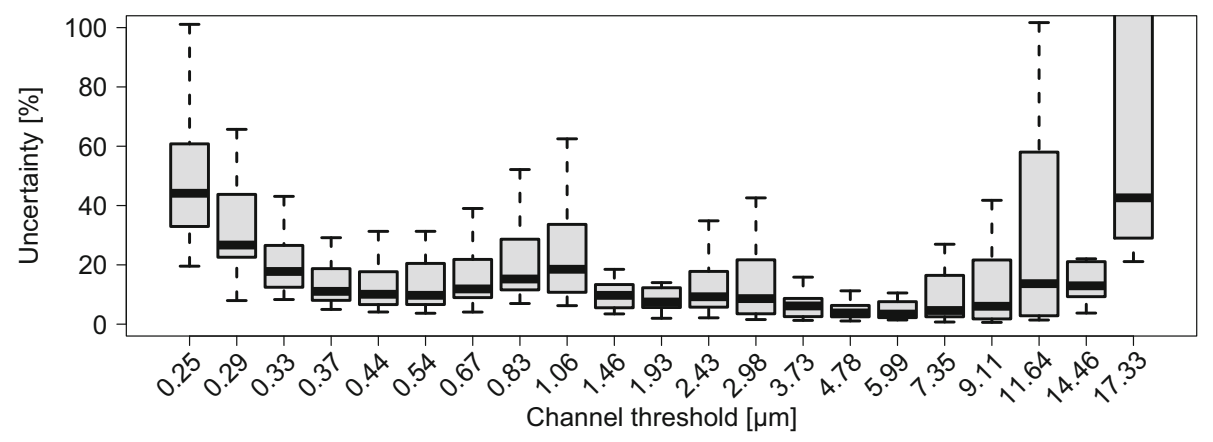

Fig. 6 Relative number flux uncertainty summarized for the fog events: 15 August 20191700 LT to 1845 LT, 16 August 20191700 LT to 1830 LT, and 19 August 20191145 LT to 1330 LT and 1645 LT to 2100 LT. Boxplots show the medians (black lines), the upper and lower quartiles (grey boxes), and the minima and maxima (whiskers) ignoring outliers

In total, the median of the relative uncertainties of the number fluxes is $11.2 \%$. El-Madany et al. (2016) calculated a relative uncertainty of the number fluxes for fog droplets in a range from $2.7 \mu \mathrm{m}$ to $50 \mu \mathrm{m}$ measured by an FM100 droplet spectrometer and obtained slightly lower values of around $10 \%$. Note that relative uncertainties above $100 \%$, which indicate that the directions of the computed fluxes are not reliable, occurred only very rarely and only for droplets of diameters larger than $14.5 \mu \mathrm{m}$.

\subsection{Size-Resolved Fog-Droplet Distribution During a Fog Event}

When a fog event occurred, the measured fog-droplet size distribution changed drastically, as shown for the first fog event of 19 August 2019 in Fig. 7. When there was no fog, such as at $1100 \mathrm{LT}$, one large peak between diameters of approximately $0.2 \mu \mathrm{m}$ and $1 \mu \mathrm{m}$ can be seen. This peak represents the concentration of non-hydrated aerosol particles, which seem to always be present. Once the fog began at 1145 LT, two more peaks started developing, one peak with a maximum at about $2 \mu \mathrm{m}$ (less pronounced) and another with a maximum droplet diameter of about $5 \mu \mathrm{m}$. The second and third peaks grew when the fog became denser and more droplets of larger size classes appeared. These peaks decreased again when the fog became lighter. When the fog was over, a distribution exhibiting only the first peak can be seen once again.

\subsection{Modelled Fog-Droplet Size Distributions and Droplet Number Fluxes}

As shown in Sect. 3.6, three local maxima are discernible in the fog-droplet size distribution under foggy conditions (cf. Fig. 7). Motivated by this observation, we model the distribution by a mixture model ("mixdist" package in R from Macdonald and Du 2018) given by a combination of three log-normal modes (cf. Fig. 8 bottom panels) (cf. Eldridge 1966; Elias et al. 2015). The model probability density $f_{\text {mix }}(d)$ is given by 
Fig.7 Qualitative change of the fog-droplet size distribution averaged over 15-min intervals during the fog event on 19 August 2019 between 1100 LT and 1400 LT

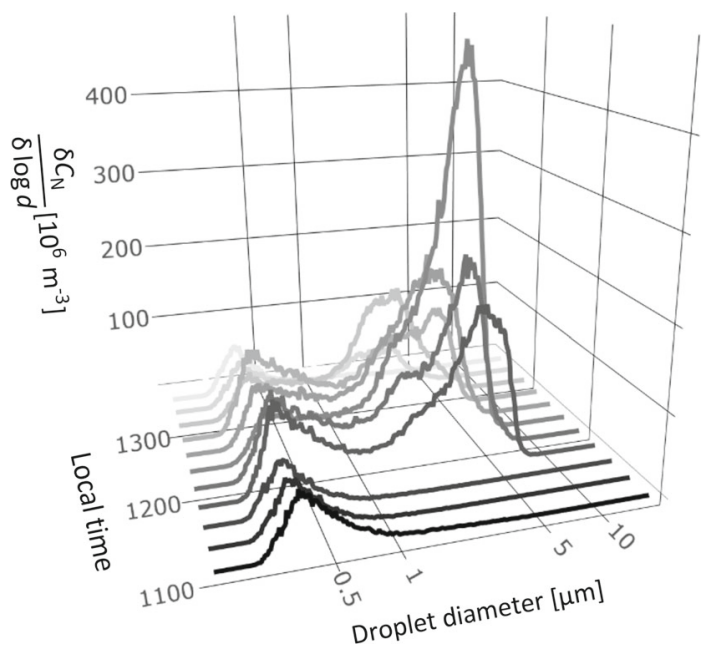

$f_{\text {mix }}(d)=\sum_{i=1}^{3} \varphi_{i} g_{\mu_{i}, \sigma_{i}}(d)$,

where $g_{\mu, \sigma}$ is the log-normal probability density parametrized by $\mu$ and $\sigma$, while $\varphi_{i}$ corresponds to the weight of the $i$-th mode (Marin et al. 2011). To clarify whether there is a correlation between the individual modes and the change in DNF directions (see Sects. 3.2 and 3.3), in Fig. 8 the DNFs are shown together with the modelled distribution of measured droplet numbers at different stages of developing fog.

In the 15-min interval before fog occurred (at 1615 LT), mean visibility was above $2000 \mathrm{~m}$ (cf. Fig. 8a). At 1700 LT the mean visibility was $1482 \mathrm{~m}$ (cf. Fig. 8b), then it decreased to $648 \mathrm{~m}$ at $1715 \mathrm{LT}$ (cf. Fig. 8c), and finally the most dense fog, with a mean visibility of $34 \mathrm{~m}$, happened at $1815 \mathrm{LT}$ (cf. Fig. 8d). Within all stages of the fog event, the position of the first mode remained almost unchanged, with a mean value around $0.4 \mu \mathrm{m}$. During the development of fog, the second mode shifted to larger size classes (the mean value changed from $0.7 \mu \mathrm{m}$ over $0.8 \mu \mathrm{m}$ to $2.3 \mu \mathrm{m}$ ), and at the last stage the mean value goes back to $1.3 \mu \mathrm{m}$. The third mode appeared at the second stage and also shifted to larger size classes (the mean value changed from $2.9 \mu \mathrm{m}$ over $4.9 \mu \mathrm{m}$ to $7.5 \mu \mathrm{m}$ ).

In general, there is a more prominent correlation between the direction of fluxes and proportion of the modes in regimes where the visibility was below $1000 \mathrm{~m}$ (stages $\mathrm{c}$ and $\mathrm{d}$ in Fig. 8). Aerosol particles of the smallest size classes had a negative flux throughout. The second mode in our fit became dominant at sizes just below the size at which the flux direction changed. The change of the flux direction back to negative fluxes correlated very well with the intersection point of the second and third mode (cf. Fig. 8c and d). The correlation of flux direction and predominant mode is less striking for the first two stages ( $a$ and $b$ ) of the fog event.

To test in greater detail the significance of the correlation between size-resolved DNFs and the three modes for foggy conditions, all size-resolved DNFs of 19 August 2019 were divided into three groups by assigning the DNFs to the mode that predominates in the corresponding size class. Afterwards, a Wilcoxon signed-rank test was executed to investigate (a) whether neighbouring groups are significantly different from each other 
(a)

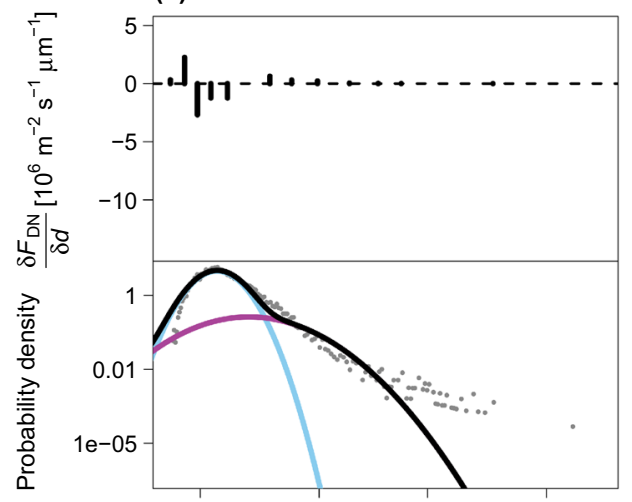

(c)

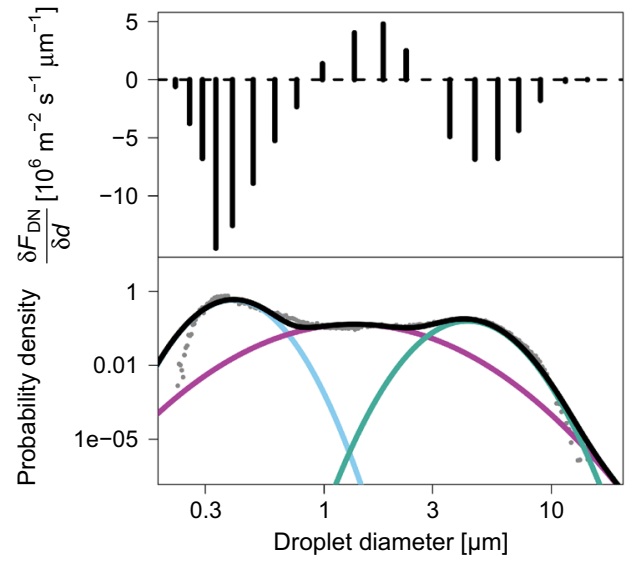

(b)

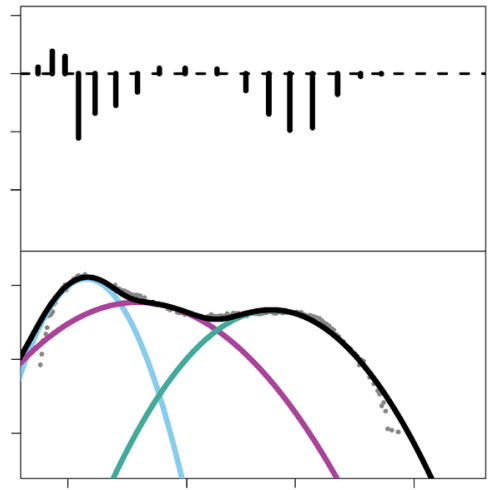

(d)

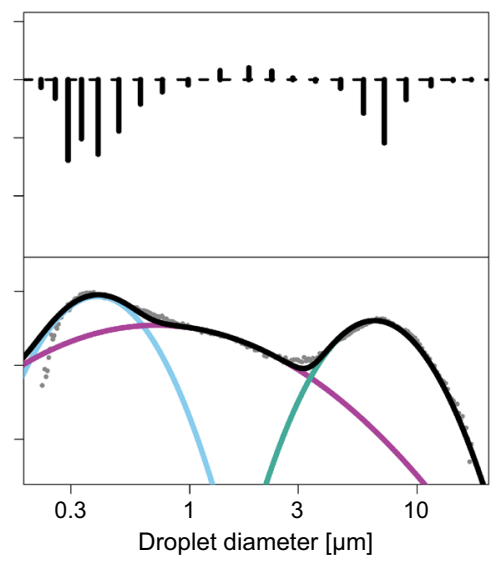

Fig. 8 Evolution of normalized size-resolved fog DNFs (upper part of each panel) and modelled probability density of log-normal-mixture distribution (bottom part of each panel) within the fog event of 19 August 2019. Measurements shown by grey dots, individual mode distribution shown by blue, purple, and green lines and combined multi-modal distribution (cf. Eq. 3) shown by a black line. Data of 15-min intervals starting at a 1615 LT, b 1700 LT, c 1715 LT, and d 1815 LT and belonging to visibility of a $>2000 \mathrm{~m}, \mathbf{b} 1482 \mathrm{~m}, \mathbf{c} 648 \mathrm{~m}$, and $\mathbf{d} 34 \mathrm{~m}$

and (b) the significance of the flux direction within the groups. The results show that the fluxes of the neighbouring groups 1 and 2 as well as 2 and 3 differ significantly ( $p$-value $\leq 0.001$ ) from each other. Furthermore, the median fluxes of group 1 and group 3 are significantly below zero, i.e., both groups have a downwards flux. The median fluxes of the second mode are significantly ( $p$-value $\leq 0.05$ ) above zero; thus, the second mode corresponds predominantly to an upward flux. 
Fig. 9 Droplet number fluxes for the three modes. Here, fluxes of each size class were assigned to groups 1-3 according to the predominant mode in the respective size class. Data taken from both fog events of 19 August 2019. Boxplots show the medians (black lines), the upper and lower quartiles (grey boxes), and the minima and maxima (whiskers) ignoring outliers (circles)

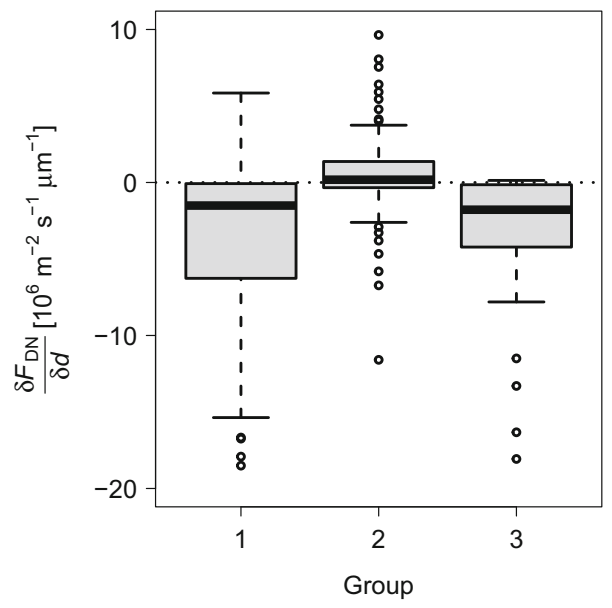

\subsection{Evolution of Droplet Number Fluxes and Modes During Fog}

To illustrate the above-described behaviour for the two fog events of 19 August 2019, Fig. 10 compares the visibility, the total DNF, the total LWF, the averaged DNFs of assigned modes, and the fog-droplet concentration in the three modes.

Here, the number of fog droplets in each mode is calculated by multiplying the weight $\varphi_{i}$ of the $i$-th mode obtained from the mixture fits with the fog-droplet concentration for every 15-min interval (cf. Fig. 10d). The total number of droplets (Fig. 10d) increased greatly within the two fog events (1150 LT to 1322 LT and 1658 LT to 2049 LT). The number of aerosol particles in the first mode was nearly constant over the whole period, increasing only slightly when fog occurred (around 1150 LT and 1658 LT); only towards the end of the period (about 1900 LT) was there a decrease of aerosol particles in the first mode towards zero even though there was still fog. As soon as the visibility decreased, the second and third modes developed and the total number of fog droplets increased (around 1150 LT, 1410 LT, 1523 LT, 1556 LT, and 1658 LT). Note that most of the droplets were within the third mode from 1930 LT onward.

The total DNF (Fig. 10b grey line) increased in a negative direction whenever visibility dropped below $1000 \mathrm{~m}$. In contrast, the total LWF (Fig. 10b black line) increased slightly in a negative direction within the first fog event (1150 LT to 1322 LT) and increased substantially in a negative direction in the second fog event (1658 LT to 2049 LT).

To compare the number of fog droplets in the three modes with the DNF directions at different times, fluxes were averaged over the droplet size classes within the interval given by averaged mean values \pm standard deviation of each mode (Fig. 10c). The fluxes of the smallest size classes had the highest variability, but during the two fog events (1150 LT to 1322 LT and 1658 LT to 2049 LT) the small aerosol particles exhibited clear negative fluxes. Fluxes of the middle and large size classes are in opposite directions. When fog occurred, the middle size classes exhibit positive fluxes, while the large size classes exhibited negative fluxes. 


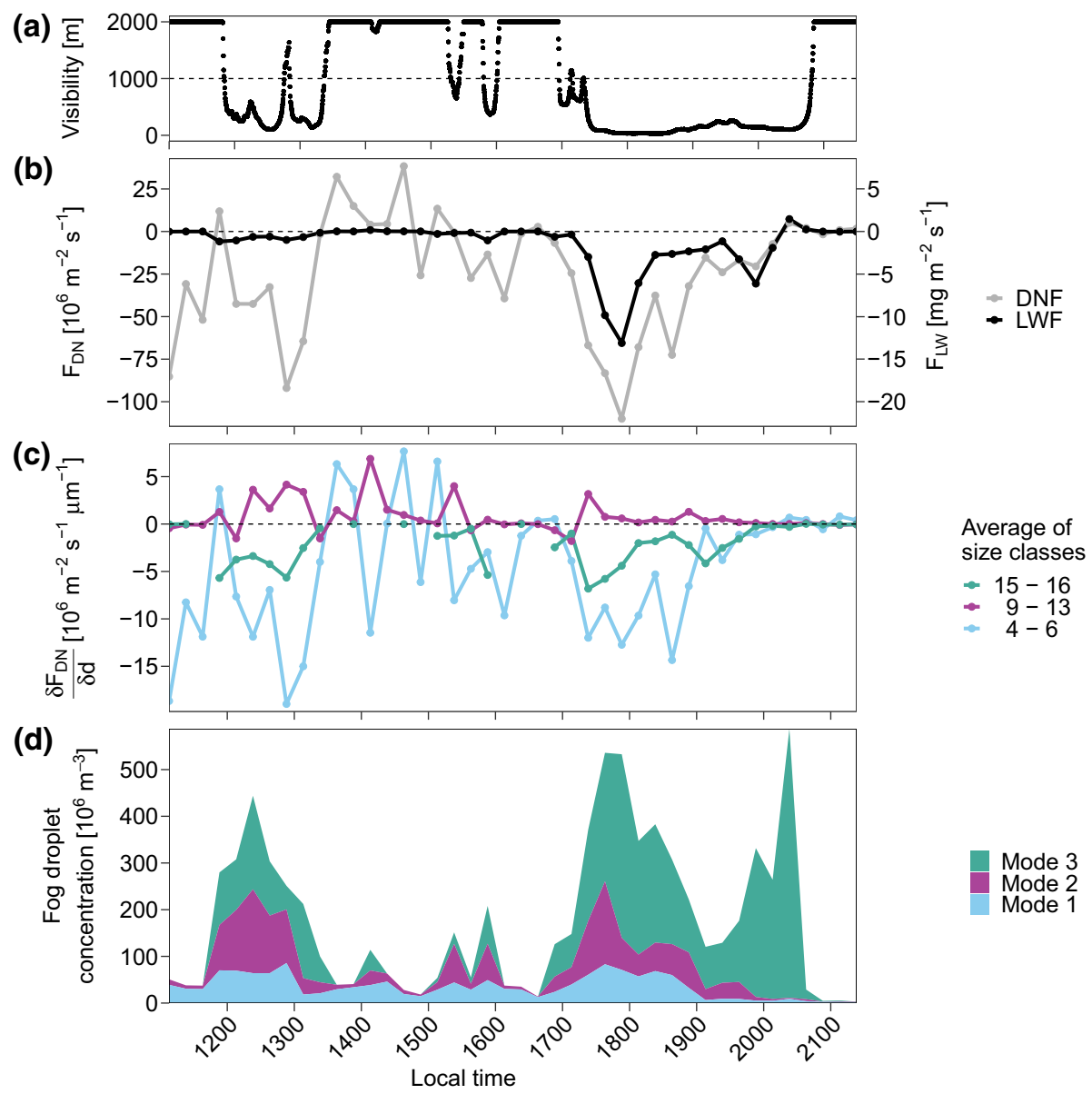

Fig. 10 Evolution during fog events of 19 August 2019 between 1100 LT and 2130 LT of a visibility (dashed line marks the threshold for fog), b total DNF (left axis) and total LWF (right axis), c averaged normalized DNFs within the averaged mean value for each of the three modes \pm 1 standard deviation for each of the three modes, d) fog-droplet concentration subdivided by the fractions of the modes

\section{Discussion}

\subsection{Classification of the Modes}

The measured fog-droplet size distributions can be described as trimodal (cf. Figs. 7 and 8). Multi-modal size distributions of fog droplets are commonly observed and can be explained by different origins of the fog and processes within it (Eldridge 1966; Bruijnzeel et al. 2006; Hammer et al. 2014; Elias et al. 2015). Additionally, the distribution of aerosol particles, which includes particles smaller than fog droplets, is multi-modal (Seinfeld and Pandis 2016).

The smallest detected mode in our study has a mean value of about $0.5 \mu \mathrm{m}$ (cf. Fig. 8) and, thus, corresponds to the so-called accumulation mode, which ranges from $0.1 \mu \mathrm{m}$ to $2 \mu \mathrm{m}$ (Seinfeld and Pandis 2016). This first mode of non-hydrated aerosol particles is present 
under both foggy and non-foggy conditions, whereas the second and third modes only appear under foggy conditions (cf. Fig. 7).

When the relative humidity increases and exceeds $100 \%$, deliquescent accumulation-mode aerosol particles start to grow by condensation; this apparently led to the formation of the second (centre) mode in Fig. 8. We infer that this mode, with a mean diameter of about $2 \mu \mathrm{m}$, consists of hydrated aerosol particles. A local minimum in the trimodal fit was found between the peaks of the second and third modes (cf. Fig. 8). Such a local minimum, as identified by Hammer et al. (2014), is the critical diameter, above which hydrated aerosol particles are activated and form droplets by rapid condensational growth. Therefore, the third mode can be classified as activated fog droplets (or activated $\mathrm{CCN}$ ). Within fog monitored in Paris, France, Elias et al. (2015) observed a transition from hydrated aerosol particles to activated fog droplets at diameters of about $2 \mu \mathrm{m}$ to $3 \mu \mathrm{m}$, and Hammer et al. (2014) found critical diameters between $1 \mu \mathrm{m}$ and $5 \mu \mathrm{m}$, with a mean value of $2.6 \mu \mathrm{m}$. These values are in good agreement with the results of our study: under foggy conditions, we also found minima between the second and third modes in a range of about $1 \mu \mathrm{m}$ to $5 \mu \mathrm{m}$. Furthermore, we can verify that the local minimum corresponds with the critical diameter using additional data on the chemical composition of the fog: from the chemical composition of fog water sampled on 16 August 2019 between 1724 LT and 1756 LT, we estimate a critical diameter at $2.2 \mu \mathrm{m}$ using the Köhler equation (Köhler 1921). This critical diameter is in good agreement with the local minimum at $1.7 \mu \mathrm{m}$, which was found in the multi-modal fit for the same time interval (not shown here).

As shown in Fig. 9 and discussed in Sect. 3.7, the three modes correlate with different flux directions within the DNFs. We therefore now refer to the above-mentioned processes of how the different modes form to explain the flux directions and to obtain a consistent general picture.

\subsection{Droplet Number Fluxes Under Foggy Conditions}

Under foggy conditions, the canopy of the forest can generally be expected to act as a sink for fog droplets. Fog droplets are formed in the atmosphere and are deposited into the ecosystem. This is reflected in our measurements by the negative total DNF and total LWF (cf. Fig. 3). However, our results also show a positive flux in certain size classes: middle-sized, hydrated aerosol particles with diameters in the range from $1 \mu \mathrm{m}$ to $2.4 \mu \mathrm{m}$ showed an upward flux, whereas small, non-hydrated aerosol particles of diameters between $0.25 \mu \mathrm{m}$ and $0.83 \mu \mathrm{m}$ and the large size classes of activated fog droplets from $3 \mu \mathrm{m}$ to $17.3 \mu \mathrm{m}$ exhibited a downward flux, as generally expected (cf. Fig. 3). These droplet size-dependent flux directions are consistent with other studies, even though the transition thresholds reported in the literature are slightly different from our results. Klemm and Wrzesinsky (2007) found a flux-direction change between a positive flux of smaller droplets and a negative flux of larger droplets at a diameter around $8 \mu \mathrm{m}$. El-Madany et al. (2016) found an upward flux for droplets from $2.7 \mu \mathrm{m}$ to $7.4 \mu \mathrm{m}$ and a downward flux for larger ones. These differences in droplet diameters at the point where the flux-direction changes can be explained by differences in the chemical composition of the droplets (El-Madany et al. 2016).

El-Madany et al. (2016) explained the phenomenon of positive flux directions in certain size classes by the Köhler theory (Köhler 1921). We now expand their explanation by additionally discussing the downward fluxes of the smallest detected non-hydrated aerosol particles. El-Madany et al. (2016) were not able to study such fluxes, because the instrumentation they used did not resolve aerosol particles with diameters smaller than $2 \mu \mathrm{m}$. 
A pool of accumulation-mode aerosols is always present, even when the relative humidity is below $100 \%$. The downward flux of these accumulation-mode aerosols indicates that the dominant process influencing their flux direction is turbulent deposition into the ecosystem (cf. Fig. 3a). The net upward flux of middle-sized hydrated aerosol particles (cf. Fig. 3a) can be explained as follows: there must be a decrease in the air temperature with increasing height above the canopy, because the sensible heat flux is positive (oriented upward; cf. Fig. $2 \mathrm{~g}$ ). Consequently, the relative humidity increases with height and eventually exceeds $100 \%$, and the non-hydrated aerosol particles transported upwards grow due to condensation. When the critical supersaturation is reached, hydrated aerosol particles will exceed their critical diameters and are activated, whereby the critical diameter is a function of the dry mass of the aerosol particles and their chemical composition (Köhler 1921). The activated droplets grow fast due to condensation, and, as a result of activation, the droplets can now exist in a relative humidity below the critical supersaturation. Thus, the droplets can grow (as long as the air masses are supersaturated), even if they are transported downwards. This downward flux is interlinked with an increase in temperature and a decrease in relative humidity. These processes result in an upward flux in the middle-size classes and a downward flux in the larger size classes (cf. Fig. 3a). This leads to an effective sink of fog droplets smaller than the critical diameter as well as a source of activated droplets in the upper part of the fog layer. With decreasing height, the relative humidity drops below 100\%. Droplets then evaporate and consequently shrink to a size at which they are in equilibrium with the surrounding air. From this state, they either deposit into the ecosystem or are subjected to upward turbulent transport and undergo the transformation again.

\subsection{Processes of Droplet Growth}

The two processes that lead to droplet growth in fog are condensation and coalescence (Elton et al. 1958). Until this point, we have only referred to growth due to condensation, which was used to explain the clear development of the flux directions (downward, upward, downward) for the first fog event (1150 LT to $1322 \mathrm{LT}$ ) and during the start of the second fog event (1658 LT to about $1930 \mathrm{LT}$ ).

To validate our explanation, two time scales are of interest. Cospectra indicate the frequency of the turbulence element, which dominates the turbulent transport of fog droplets. From this dominant frequency, the time of turbulent exchange $T_{\text {turb }}$ can be estimated. The analysis of the cospectra of the fog events of 19 August 2019 gives an exchange time $T_{\text {turb }}$ of about $90 \mathrm{~s}$ (data not shown in detail). Regarding the time scale for droplet growth, we roughly estimated a typical time $T_{\text {grow }} \approx 23 \mathrm{~s}$ of condensational growth of aerosol particles from the smallest size class $(0.25 \mu \mathrm{m})$ to droplets of the largest size class $(17.33 \mu \mathrm{m})$ using a calculation based on an extension of Maxwellian condensation growth theory (Maxwell 1890 ), assuming a fixed air temperature of $20^{\circ} \mathrm{C}$. We define the ratio $B_{\mathrm{t}}$ of the two time scales as

$$
B_{\mathrm{t}}=\frac{T_{\text {turb }}}{T_{\text {grow }}} .
$$

Since $B_{\mathrm{t}} \approx 3.9$, condensational growth from the smallest to the largest size class is possible within a turbulence element. Thus, small aerosol particles can be transformed from their size class to larger ones while they are being transported upwards. This is a necessary prerequisite for explaining the positive DNFs of the middle-size classes given above. 
However, we cannot exclude that growth occurred due to coalescence. Liu et al. (2011) and Degefie et al. (2015a) described the occurrence of coalescence as a driver for droplet growth, especially in the later stages of a fog event. At that stage, a higher number of large droplets is present, which have a higher collection efficiency (Elton et al. 1958). The process of coalescence also includes collection scavenging and, thus, a washing out of aerosol particles and cleaning of the air masses (Seinfeld and Pandis 2016). Zhu et al. (2019) found out that fog scavenges the air by reducing the number of particles smaller than $2.5 \mu \mathrm{m}$ by about $70 \%$. We hypothesize that coalescence occurred at the end of the second fog event of 19 August 2019 (about 1930 LT to 2049 LT). We infer this presumption from the observation that the numbers of aerosol particles in the first and second modes decreased (cf. Fig. 10d), meaning that the mean droplet diameter of the existing droplets increased (cf. Fig. 4b).

\subsection{Evolution and Dissipation of the Two Fog Events}

Comparing the first fog event (1150 LT to 1322 LT) and the second fog event (1658 LT to 2049 LT) of 19 August 2019, the fog of the first event was less dense, of shorter duration, and had a lower total droplet number than the second fog event of 19 August 2019 (cf. Fig. 10).

Within the first fog event, the visibility decreased rapidly, but it fluctuated during the entire event. When the visibility was below $1000 \mathrm{~m}$, the different flux directions developed, which indicates that the droplets grew due to condensation, as described in Sect. 4.3. Moreover, the total LWF was low whereas the total DNF was high in a negative direction, due to the dominance of small droplets within the total DNF (cf. Fig. 10); not many droplets were larger than $6.1 \mu \mathrm{m}$ (cf. Fig. 4). By comparison, the second fog event had a larger negative total LWF, which can be explained by a downward DNF of larger droplets that contain larger amounts of water per droplet. Besides, Fig. 4b shows that a considerable number of droplets up to 11.6 $\mu \mathrm{m}$ was detected. Presumably, the droplet growth within the second fog event (1658 LT to 2049 LT) started with condensational growth as the main process (as in the first fog event), and coalescence started later because larger droplets must have developed by condensational growth in order to coalesce with smaller aerosol particles.

The dissipation of fog was also different for the two fog events on 19 August 2019. At the end of the first fog event (around 1322 LT), when visibility increased above $1000 \mathrm{~m}$, positive fluxes of nearly all size classes were present (cf. Fig. 4). A possible reason for this could be evaporation due to warming of the airmasses above the fog by the sun. The sensible heat flux decreased towards the end of the fog event, which indicates an evening out of the vertical temperature gradient within the fog layer (cf. Fig. 2). Moreover, the relative humidity decreased at the end of the fog event for a short time period. After dissipation of the fog, only some small aerosol particles remained (cf. Fig. 4).

Due to an increase of the relative humidity to $100 \%$ shortly after the first fog event combined with a visibility of more than $2000 \mathrm{~m}$, we suppose that the fog developed at a higher level up the slope above the measurement tower between both fog events (cf. Fig. 2e).

In contrast, when the second fog event ended (around 2049 LT) and visibility increased above $1000 \mathrm{~m}$, the number of droplets and the fluxes were around zero (cf. Fig. 4). The disappearance of all fluxes at the end of the second fog event can be explained by the previous coalescence and, therefore, a reduction of the aerosol particle number in the small and middlesize classes. In addition, the change of the wind direction implies adiabatic heating due to a downhill transport of air masses, which reinforces the dissipation of fog (cf. Fig. 2a). Here again, some accumulation-mode aerosols remained, but a significantly lower number than in the first fog event (cf. Fig. 4). 


\section{Conclusion}

Bidirectional turbulent fluxes of fog droplets were measured between 27 July 2019 and 19 August 2019 at the top of a 40-m high tower in a subtropical montane cloud forest in Xitou, Taiwan. We used a new set-up for detecting size-resolved DNFs and LWFs: we integrated an aerosol spectrometer (WELAS aerosol sensor 2300) into an eddy-covariance set-up, which enables the detection of size-resolved fog-droplet fluxes of smaller size than in previous studies (e.g., Klemm and Wrzesinsky 2007; El-Madany et al. 2016). Within our measurement range of non-hydrated aerosol particles and fog droplet diameters between $0.25 \mu \mathrm{m}$ and $17.3 \mu \mathrm{m}$, two flux-direction changes of the DNFs were detected: non-hydrated aerosol particles from $0.25 \mu \mathrm{m}$ to $0.83 \mu \mathrm{m}$ show downward fluxes, hydrated aerosol particles within the size classes from $1.1 \mu \mathrm{m}$ to $2.4 \mu \mathrm{m}$ show upward fluxes, and the direction of fluxes of droplets larger than $3 \mu \mathrm{m}$ is downward again.

The fog-droplet size distribution exhibits three modes over the measured size spectrum and was modelled by a trimodal log-normal distribution. The three modes correlated with the different flux directions, thus we conclude that the same processes are responsible for the differentiation of the modes and the DNFs. The first mode of the smallest aerosol particles contained accumulation-mode aerosols, which can grow by condensation and form a second mode (in the middle size classes) consisting of hydrated aerosol particles. The third mode (largest size classes) corresponded to activated droplets.

The results shown by El-Madany et al. (2016) for a similar montane cloud forest in Taiwan were qualitatively reproduced in our study, i.e., the upper part of the fog layer is an effective sink for hydrated aerosol particles, while the forest canopy is a sink for activated fog droplets. This can be explained by a conjunction of the Köhler theory with the turbulent transport of fog droplets at the given vertical temperature gradient: hydrated aerosol particles reach cooler and, thus, more humid air masses during upward transport, whereby they grow due to condensation and become activated fog droplets by reaching the critical diameter; subsequently, they grow even more rapidly and even continue growing during downward transport. We support this reasoning via the estimation of the critical diameters of fog droplets from the chemical analysis of fog.

The present study confirms this previous observation of size-dependent sink-source dynamics and expands it towards smaller aerosol particles by showing a deposition flux of aerosol particles smaller than $1.1 \mu \mathrm{m}$ in diameter into the ecosystem. These accumulationmode aerosols can also grow due to condensation during uplifting within turbulence elements and become activated to fog droplets; alternatively, they can be deposited into the ecosystem. The latter process seems to be the predominant one, since a net deposition flux was found.

Condensational growth is associated with the distinct development of the flux directions (downward, upward, downward). The analysis of the time scales of condensational growth and of the turbulent transport validated the explanation of the process according to Köhler theory: condensational growth of an accumulation-mode aerosol of $0.25 \mu \mathrm{m}$ to an activated droplet of $17.3 \mu \mathrm{m}$ is possible within the transport time of a turbulence element. However, when the different flux directions are not clearly separable and more large droplets are present, coalescence is also a driver for droplet growth.

For a better understanding of the downward flux of the accumulation-mode aerosols under foggy conditions, further research is necessary. A separate measurement of the deliquescent aerosol particles and dry aerosol particles would be helpful to distinguish both groups and to better assess the involved processes, since knowing the total number of deliquescent aerosol particles and dry aerosol particles would help to interpret the downward fluxes of the smallest 
measured aerosol particles. Further, chemical analysis of single accumulation-mode aerosol particles or fog droplets, for example by mass spectrometric methods, would allow for a more detailed analysis of the dynamics and processes driving biosphere-atmosphere exchange of fog.

Acknowledgements We are grateful to the Experimental Forest Xitou and the National Taiwan University for facilitating and supporting the measurements in Taiwan. We thank Celeste Brennecka for language editing of the manuscript. This work was financially supported by the German Academic Exchange Service (DAAD) and the Ministry of Science and Technology of Taiwan (MOST) within their Project-based Personnel Exchange Program (PPP) "Studies on Fog and Cloud Chemistry with Optimized Temporal Resolution". Last but not least, we thank two anonymous reviewers for very helpful comments on an earlier version of this manuscript.

Funding Open Access funding enabled and organized by Projekt DEAL.

Open Access This article is licensed under a Creative Commons Attribution 4.0 International License, which permits use, sharing, adaptation, distribution and reproduction in any medium or format, as long as you give appropriate credit to the original author(s) and the source, provide a link to the Creative Commons licence, and indicate if changes were made. The images or other third party material in this article are included in the article's Creative Commons licence, unless indicated otherwise in a credit line to the material. If material is not included in the article's Creative Commons licence and your intended use is not permitted by statutory regulation or exceeds the permitted use, you will need to obtain permission directly from the copyright holder. To view a copy of this licence, visit http://creativecommons.org/licenses/by/4.0/.

\section{References}

Ahmed MM, Abdel-Aty M, Lee J, Yu R (2014) Real-time assessment of fog-related crashes using airport weather data: a feasibility analysis. Accid Anal Prev 72:309-317. https://doi.org/10.1016/j.aap.2014.07. 004

Beiderwieden E, Wolff V, Hsia YJ, Klemm O (2008) It goes both ways: measurements of simultaneous evapotranspiration and fog droplet deposition at a montane cloud forest. Hydrol Proc 22(21):4181-4189. https://doi.org/10.1002/hyp.7017

Bruijnzeel L, Eugster W, Burkard R (2006) Fog as a hydrologic input. In: Anderson M (ed) Encyclopedia of hydrological sciences, Wiley, Chichester, pp 559-582

Buzorius G, Rannik Ü, Nilsson E, Vesala T, Kulmala M (2003) Analysis of measurement techniques to determine dry deposition velocities of aerosol particles with diameters less than $100 \mathrm{~nm}$. J Aerosol Sci 34(6):747-764. https://doi.org/10.1016/S0021-8502(03)00025-9

Chen CL, Chen TY, Hung HM, Tsai PW, Chou CCK, Chen WN (2021) The influence of upslope fog on hygroscopicity and chemical composition of aerosols at a forest site in Taiwan. Atmos Environ 246:118150. https://doi.org/10.1016/j.atmosenv.2020.118150

Dawson TE (1998) Fog in the California redwood forest: ecosystem inputs and use by plants. Oecologia 117(4):476-485. https://doi.org/10.1007/s004420050683

Degefie D, El-Madany TS, Hejkal J, Held M, Dupont JC, Haeffelin M, Klemm O (2015a) Microphysics and energy and water fluxes of various fog types at SIRTA, France. Atmos Res 151:162-175. https://doi.org/ 10.1016/j.atmosres.2014.03.016

Degefie D, El-Madany TS, Held M, Hejkal J, Hammer E, Dupont JC, Haeffelin M, Fleischer E, Klemm O (2015b) Fog chemical composition and its feedback to fog water fluxes, water vapor fluxes, and microphysical evolution of two events near Paris. Atmos Res 164:328-338. https://doi.org/10.1016/j. atmosres.2015.05.002

Deventer MJ, Griessbaum F, Klemm O (2013) Size-resolved flux measurement of sub-micrometer particles over an urban area. Meteorol Z 22(6):729-737. https://doi.org/10.1127/0941-2948/2013/0441

El-Madany TS, Griessbaum F, Fratini G, Juang JY, Chang SC, Klemm O (2013) Comparison of sonic anemometer performance under foggy conditions. Agric For Meteorol 173:63-73. https://doi.org/10. 1016/j.agrformet.2013.01.005

El-Madany TS, Walk JB, Deventer MJ, Degefie DT, Chang SC, Juang JY, Griessbaum F, Klemm O (2016) Canopy-atmosphere interactions under foggy condition-size-resolved fog droplet fluxes and their implications. J Geophys Res Biogeo 121(3):796-808. https://doi.org/10.1002/2015JG003221

Eldridge RG (1966) Haze and fog aerosols distribution. J Atmos Sci 23(5):605-613 
Elias T, Haeffelin M, Drobinski P, Gomes L, Rangognio J, Bergot T, Chazette P, Raut JC, Colomb M (2009) Particulate contribution to extinction of visible radiation: pollution, haze, and fog. Atmos Res 92(4):443454. https://doi.org/10.1016/j.atmosres.2009.01.006

Elias T, Dupont JC, Hammer E, Hoyle CR, Haeffelin M, Burnet F, Jolivet D (2015) Enhanced extinction of visible radiation due to hydrated aerosols in mist and fog. Atmos Chem Phys 15(12):6605-6623. https:// doi.org/10.5194/acp-15-6605-2015

Elton GAH, Mason BJ, Picknett RG (1958) The relative importance of condensation and coalescence processes on the stability of a water fog. J Chem Soc, Faraday Trans 54:1724-1730. https://doi.org/10.1039/ tf9585401724

Eugster W (2008) Fog research. Erde 139(1-2):1-10

Flores JM, Trainic M, Borrmann S, Rudich Y (2009) Effective broadband refractive index retrieval by a white light optical particle counter. Phys Chem Chem Phys 11(36):7943-7950

Foken T, Wichura B (1996) Tools for quality assessment of surface-based flux measurements. Agric For Meteorol 78(1-2):83-105. https://doi.org/10.1016/0168-1923(95)02248-1

Foken T, Gockede M, Mauder M, Mahrt L, Amiro B, Munger W (2005) Post-field data quality control. In: Lee X, Massman W, Law B (eds) Handbook of micrometeorology: a guide for surface flux measurement and analysis, Springer, Netherlands, Dordrecht, pp 181-208, https://doi.org/10.1007/1-4020-2265-4_9

Foken T, Aubinet M, Leuning R (2012) The eddy covariance method. In: Aubinet M, Vesala T, Papale D (eds) Eddy covariance: a practical guide to measurement and data analysis, Springer Netherlands, Dordrecht, pp 1-19, https://doi.org/10.1007/978-94-007-2351-1_1

Fultz AJ, Ashley WS (2016) Fatal weather-related general aviation accidents in the United States. Phys Geogr 37(5):291-312. https://doi.org/10.1080/02723646.2016.1211854

Gultepe I, Tardif R, Michaelides SC, Cermak J, Bott A, Bendix J, Müller MD, Pagowski M, Hansen B, Ellrod G, Jacobs W, Toth G, Cober SG (2007) Fog research: a review of past achievements and future perspectives. Pure Appl Geophys 164(6-7):1121-1159. https://doi.org/10.1007/s00024-007-0211-X

Gultepe I, Fernando H, Pardyjak E, Hoch S, Silver Z, Creegan E, Leo L, Pu Z, De Wekker S, Hang C (2016) An overview of the MATERHORN fog project: observations and predictability. Pure Appl Geophys 173(9):2983-3010. https://doi.org/10.1007/s00024-016-1374-0

Haeffelin M, Bergot T, Elias T, Tardif R, Carrer D, Chazette P, Colomb M, Drobinski P, Dupont E, Dupont JC, Gomes L, Musson-Genon L, Pietras C, Plana-Fattori A, Protat A, Rangognio J, Raut JC, Rémy S, Richard D, Sciare J, Zhang X (2010) PARISFOG: shedding new light on fog physical processes. Bull Am Meteorol Soc 91(6):767-783. https://doi.org/10.1175/2009BAMS2671.1

Hammer E, Gysel M, Roberts GC, Elias T, Hofer J, Hoyle CR, Bukowiecki N, Dupont JC, Burnet F, Baltensperger U, Weingartner E (2014) Size-dependent particle activation properties in fog during the ParisFog 2012/13 field campaign. Atmos Chem Phys 14(19):10517-10533. https://doi.org/10.5194/acp14-10517-2014

Hanesiak JM, Wang XL (2005) Adverse-weather trends in the Canadian arctic. J Clim 18(16):3140-3156. https://doi.org/10.1175/JCLI3505.1

Hinds WC (1999) Aerosol technology: properties, behavior, and measurement of airborne particles, 2nd edn. Wiley, New York

Horst TW (1997) A simple formula for attenuation of eddy fluxes measured with first-order-response scalar sensors. Boundary-Layer Meteorol 82(2):219-233. https://doi.org/10.1023/A:1000229130034

Hudson JG (1980) Relationship between fog condensation nuclei and fog microstructure. J Atmos Sci 37(8):1854-1867

Ju J, Bai H, Zheng Y, Zhao T, Fang R, Jiang L (2012) A multi-structural and multi-functional integrated fog collection system in cactus. Nat Commun 3(1):1-6. https://doi.org/10.1038/ncomms2253

Klemm O, Lin NH (2016) What causes observed fog trends: air quality or climate change? Aerosol Air Qual Res 16(5):1131-1142. https://doi.org/10.4209/aaqr.2015.05.0353

Klemm O, Wrzesinsky T (2007) Fog deposition fluxes of water and ions to a mountainous site in Central Europe. Tellus Ser B Chem Phys Meteorol 59(4):705-714. https://doi.org/10.1111/j.1600-0889.2007. 00287.x

Klemm O, Chang SC, Hsia YJ (2006) Energy fluxes at a subtropical mountain cloud forest. For Ecol Manag 224(1-2):5-10. https://doi.org/10.1016/j.foreco.2005.12.003

Klemm O, Schemenauer RS, Lummerich A, Cereceda P, Marzol V, Corell D, van Heerden J, Reinhard D, Gherezghiher T, Olivier J, Osses P, Sarsour J, Frost E, Estrela MJ, Valiente JA, Fessehaye GM (2012) Fog as a fresh-water resource: overview and perspectives. Ambio 41(3):221-234. https://doi.org/10. $1007 / \mathrm{s} 13280-012-0247-8$

Köhler H (1921) Zur Kondensation des Wasserdampfes in der Atmosphäre. Geofys Publ 2(3)

Liang YL, Lin TC, Hwong JL, Lin NH, Wang CP (2009) Fog and precipitation chemistry at a mid-land forest in central Taiwan. J Environ Qual 38(2):627-636. https://doi.org/10.2134/jeq2007.0410 
Liu D, Yang J, Niu S, Li Z (2011) On the evolution and structure of a radiation fog event in Nanjing. Adv Atmos Sci 28(1):223-237. https://doi.org/10.1007/s00376-010-0017-0

Macdonald P, Du J (2018) Mixdist: finite mixture distribution models. R Package Version 0.5-5

Mammarella I, Peltola O, Nordbo A, Järvi L, Rannik Ü (2016) Quantifying the uncertainty of eddy covariance fluxes due to the use of different software packages and combinations of processing steps in two contrasting ecosystems. Atmos Meas Technol 9:4915-4933. https://doi.org/10.5194/amt-9-4915-2016

Maneke-Fiegenbaum F, Klemm O, Lai YJ, Hung CY, Yu JC (2018) Carbon exchange between the atmosphere and a subtropical evergreen mountain forest in Taiwan. Adv Meteorol 2018:1-12. https://doi.org/10. $1155 / 2018 / 9287249$

Marin J, Mengersen K, Robert C (2011) Bayesian modelling and inference on mixtures of distributions. In: Dey D, Rao C (eds) Bayesian thinking - modeling and computation, no. 25 in Handbook of Statistics, Elsevier, pp 459-507

Maxwell JC (1890) Diffusion. In: Niven WD (ed) The scientific papers of James clerk maxwell, vol 2. Cambridge University Press, Cambridge, pp 625-646

Moncrieff J, Massheder J, de Bruin H, Elbers J, Friborg T, Heusinkveld B, Kabat P, Scott S, Soegaard H, Verhoef A (1997) A system to measure surface fluxes of momentum, sensible heat, water vapour and carbon dioxide. J Hydrol 188:589-611. https://doi.org/10.1016/S0022-1694(96)03194-0

Mölter L, Keßler P (2004) Partikelgrößen- und Partikelanzahlbestimmung in der Außenluft mit einem neuen optischen Aerosolspektrometer. Gefahrstoffe - Reinhaltung der Luft 64(10):439-447

Parker AR, Lawrence CR (2001) Water capture by a desert beetle. Nature 414:33-34. https://doi.org/10.1038/ 35102108

Rannik Ü, Vesala T (1999) Autoregressive filtering versus linear detrending in estimation of fluxes by the eddy covariance method. Boundary-Layer Meteorol 91(2):259-280. https://doi.org/10.1023/A: 1001840416858

Rømer H, Petersen HJS, Haastrup P (1995) Marine accident frequencies - review and recent empirical results. J Navig 48(3):410-424. https://doi.org/10.1017/S037346330001290X

Seinfeld JH, Pandis SN (2016) Atmospheric chemistry and physics: from air pollution to climate change, 3rd edn. Wiley, New York

Simon S, Klemm O, El-Madany TS, Walk J, Amelung K, Lin PH, Chang SC, Lin NH, Engling G, Hsu SC, Wey TH, Wang YN, Lee YC (2015) Chemical composition of fog water at four sites in Taiwan. Aerosol Air Qual Res 16(3):618-631. https://doi.org/10.4209/aaqr.2015.03.0154

Vautard R, Yiou P, van Oldenborgh GJ (2009) Decline of fog, mist and haze in Europe over the past 30 years. Nat Geosci 2(2):115-119. https://doi.org/10.1038/ngeo414

Vickers D, Mahrt L (1997) Quality control and flux sampling problems for tower and aircraft data. J Atmos Ocean Technol 14(3):512-526

Vong R, Kowalski A (1995) Eddy correlation measurements of size-dependent cloud droplet turbulent fluxes to complex terrain. Tellus Ser B Chem Phys Meteorol 47(3):331-352

Wang YN, Chiang PN, Wey TH, Lai YJ, Yu JC, Tsai MJ (2011) Long-term ecosystem research sites in Taiwan - the Xitou and Pingdong forest CO2 flux tower stations. AsiaFlux Newsletter 33:6-7

Webb EK, Pearman GI, Leuning R (1980) Correction of flux measurements for density effects due to heat and water vapour transfer. Q J R Meteorol Soc 106(447):85-100. https://doi.org/10.1002/qj.49710644707

Westbeld A, Klemm O, Grießbaum F, Sträter E, Larrain H, Osses P, Cereceda P (2009) Fog deposition to a Tillandsia carpet in the Atacama Desert. Ann Geophys 27(9):3571-3576. https://doi.org/10.5194/angeo27-3571-2009

Wey T, Lai Y, Chang C, Shen C, Hong C, Wang Y, Chen M (2011) Preliminary studies on fog characteristics at Xitou region of central Taiwan. J Exp For Natl Taiwan Univ 25(2):149-160

Whiteman C, Zardi D (2013) Diurnal mountain wind systems. In: Chow FK, De Wekker SF, Snyder BJ (eds) Mountain weather research and forecasting: recent progress and current challenges, springer atmospheric sciences, Springer Netherlands, Dordrecht, pp 35-119. https://doi.org/10.1007/978-94-007-4098-3

Wilczak JM, Oncley SP, Stage SA (2001) Sonic anemometer tilt correction algorithms. Boundary-Layer Meteorol 99(1):127-150. https://doi.org/10.1023/A:1018966204465

World Meteorological Organization (ed) (1992) International meteorological vocabulary, 2nd edn. No. 182 in WMO/OMM/VMO, Secretariat of the World Meteorological Organization, Geneva, Switzerland

Zhang X, Musson-Genon L, Dupont E, Milliez M, Carissimo B (2014) On the influence of a simple microphysics parametrization on radiation fog modelling: a case study during ParisFog. Boundary-Layer Meteorol 151(2):293-315. https://doi.org/10.1007/s10546-013-9894-y 
Zhu J, Zhu B, Huang Y, An J, Xu J (2019) PM2.5 vertical variation during a fog episode in a rural area of the Yangtze River Delta. China. Sci Total Environ 685:555-563. https://doi.org/10.1016/j.scitotenv.2019. 05.319

Publisher's Note Springer Nature remains neutral with regard to jurisdictional claims in published maps and institutional affiliations. 